\title{
UKURAN ENTROPI BARU UNTUK HIMPUNAN KABUR INTUISIONISTIK
}

\author{
WINDI ADRIAN SUKRI, YANITA \\ Program Studi S1 Matematika, \\ Fakultas Matematika dan Ilmu Pengetahuan Alam, Universitas Andalas, \\ Kampus UNAND Limau Manis Padang, Indonesia. \\ email : windisukri@gmail.com
}

Diterima 9 Maret 2019 Direvisi 7 April 2019 Dipublikasikan 7 Mei 2019

\begin{abstract}
Abstrak. Himpunan kabur (fuzzy set/FS) hadir atau diperkenalkan untuk mengatasi permasalahan dalam kehidupan sehari-hari yang banyak mengandung unsur ketidakjelasan. Himpunan kabur ini diperkenalkan oleh L.A. Zadeh (1965). Kemudian beberapa bentuk umum dari himpunan kabur telah diusulkan dan dipelajari untuk mengatasi ketidakjelasan. Salah satunya ada himpunan kabur intuisionistik (Intuitionistic Fuzzy Sets/IFS). Dalam teori himpunan kabur ada salah satu topik penting yang telah diteliti serta diusulkan oleh banyak peneliti, yaitu ukuran entropi himpunan kabur intuisionistik. Pada tulisan ini akan diusulkan ukuran entropi baru untuk himpunan kabur intuisionistik, serta bagaimana perbandingan antara ukuran entropi baru tersebut dengan beberapa ukuran entropi yang pernah diusulkan sebelumnya.
\end{abstract}

Kata Kunci: himpunan kabur, himpunan kabur intuisionistik, ukuran entropi

\section{Pendahuluan}

Dalam himpunan kabur ada salah satu topik penting yang telah diteliti oleh banyak peneliti dari berbagai sudut pandang, yaitu ukuran entropi himpunan kabur intuisionistik IFS. Ukuran entropi dari himpunan kabur intuisionistik menggambarkan tingkat kekaburan dari himpunan kabur intuisionistik itu sendiri. Banyak peneliti yang telah mengusulkan ukuran entropi berbeda dari himpunan kabur intuisionistik [8] [9] [11] [12].

Dalam bebrapa kasus terdapat kekurangan dari ukuran entropi yang telah diusulkan oleh [8] [9] [11] [12]. Oleh karena itu, pada penelitian ini akan diusulkan ukuran entropi baru untuk himpunan kabur intuisionistik, serta bagaimana perbandingan antara ukuran entropi baru tersebut dengan beberapa ukuran entropi yang pernah diusulkan sebelumnya.

\section{Landasan Teori}

\subsection{Himpunan Kabur}

Himpunan kabur diperkenalkan oleh Lotfi A. Zadeh [13] pada tahun 1965. Pada himpunan kabur, keanggotaan suatu unsur dinyatakan dalam derajat keanggotaan 
yang nilainya terletak dalam interval $[0,1]$ dan ditentukan dengan fungsi keanggotaan $u_{A}: X \rightarrow[0,1]$.

Definisi 2.1. [13] Misalkan X adalah suatu himpunan semesta. Himpunan kabur (FS) A atas $X$ didefinisikan sebagai:

$$
A=\left\{\left(x, u_{A}(x)\right) \mid x \in X\right\},
$$

dimana $u_{A}: X \rightarrow[0,1]$, dan $u_{A}(x)$ disebut derajat keanggotaan atas $x \in X$ pada himpunan kabur A. Kemudian komplemen dari A didefinisikan sebagai

$$
A^{c}=\left\{\left(x, 1-u_{A}(x)\right) \mid x \in X\right\} .
$$

\subsection{Himpunan Kabur Intuisionistik}

Definisi 2.2. [1] Misalkan $X$ adalah suatu himpunan semesta. Himpunan kabur intuisionistik (IFS) A atas $X$ adalah

$$
A=\left\{\left(x, u_{A}(x), v_{A}(x)\right) \mid x \in X\right\},
$$

dimana $u_{A}: X \rightarrow[0,1]$ dan $v_{A}: X \rightarrow[0,1]$ berturut-turut menyatakan fungsi keanggotaan dan fungsi ketidakanggotaan atas $X$ pada himpunan $A, u_{A}(x)$ disebut derajat keanggotaan atas $x \in X$ pada himpunan $A, v_{A}(x)$ disebut derajat ketidakanggotaan atas $x \in X$ pada himpunan $A$. Selanjutnya untuk setiap $x \in X$ harus memenuhi:

$$
0 \leqslant u_{A}(x)+v_{A}(x) \leqslant 1
$$

dan $\pi_{A}(x)=1-u_{A}(x)-v_{A}(x)$ disebut derajat keragu-raguan keanggotaan atas $x \in X$ pada IFS $A$, artinya $\pi_{A}(x)$ menyatakan ketidaktahuan apakah $x$ mempunyai derajat keanggotaan atau tidak pada IFS dengan $\pi_{A}: X \rightarrow[0,1]$ untuk setiap $x \in X$. Kemudian Komplemen dari A didefinisikan sebagai:

$$
A^{c}=\left\{\left(x, v_{A}(x), u_{A}(x)\right) \mid x \in X\right\} .
$$

\subsection{Ukuran Entropi Himpunan Kabur Intuisionistik}

Menurut De Luca dan Termini [6] ukuran tingkat ketidakjelasan atau kekaburan disebut ukuran entropi .

Definisi 2.3. [7] Misalkan $X$ adalah suatu himpunan semesta, IFS $(X)$ adalah himpunan dari semua himpunan kabur intuisionistik atas $X$, dan $A=\left\{\left(x, u_{A}(x)\right.\right.$, $\left.\left.v_{A}(x)\right) \mid x \in X\right\}$ adalah suatu himpunan kabur intuisionistik atas X. Sebuah fungsi bernilai riil E: $\operatorname{IFS}(X) \rightarrow[0,1]$ adalah ukuran entropi pada IFS $(X)$, jika E memenuhi syarat berikut:

(E1) $E(A)=0$ jika dan hanya jika $A$ adalah suatu himpunan tegas; yaitu, $u_{A}(x)=1$ atau $u_{A}(x)=0$ untuk setiap $x \in X$;

(E2) $E(A)=1$ jika dan hanya jika $u_{A}(x)=v_{A}(x)$ untuk setiap $x \in X$; 
(E3) $E(A)=E\left(A^{c}\right)$;

(E4) $E(A) \leqslant E(B)$ jika $u_{A}(x) \geqslant u_{B}(x)$ dan $v_{B}(x) \geqslant v_{A}(x)$ untuk $u_{B}(x) \geqslant v_{B}(x)$, atau $u_{A}(x) \leqslant u_{B}(x)$ dan $v_{B}(x) \leqslant v_{A}(x)$ untuk $u_{B}(x) \leqslant v_{B}(x)$, untuk setiap $x \in X$.

\section{Pembahasan}

Pada bagian ini akan diusulkan ukuran entropi untuk IFS dan akan ditunjukkan efisiensi melalui perbandingan dengan beberapa ukuran entropi yang ada di [8] [9] [11] [12].

\subsection{Sebuah Ukuran Entropi Baru untuk IFS}

Szmidt dan Kacprzyk [7] memperluas aksioma dari De Luca dan Termini [6] untuk mengusulkan fungsi berikut sebagai suatu ukuran entropi untuk IFS. Dalam subbagian ini, akan diperkenalkan sebuah ukuran entropi baru untuk IFS. Untuk suatu $A=\left\{\left(x_{i}, u_{A}\left(x_{i}\right), v_{A}\left(x_{i}\right)\right) \mid x_{i} \in X\right\} \in \operatorname{IFS}(X), E(A)$ didefinisikan sebagai:

$$
E(A)=\frac{1}{n} \sum_{i=1}^{n} \cos \frac{u_{A}\left(x_{i}\right)-v_{A}\left(x_{i}\right)}{2\left(1+\pi_{A}\left(x_{i}\right)\right)} \pi
$$

dan $E(A)$ adalah fungsi yang terdefinisi dengan baik [10].

Teorema 3.1. [10] Pemetaan E(A), yang didefinisikan oleh persamaan (3.1), merupakan ukuran entropi untuk IFS.

$E(A)$ yang didefinisikan pada persamaan (3.1) merupakan suatu ukuran entropi.

Teorema 3.2. [10] Misalkan $f:[-1,1] \rightarrow[0,1]$ fungsi genap sedemikian sehingga $f$ adalah monoton naik pada $[0,1], f(-1)=f(1)=0$, dan $f(0)=1$. Untuk IFS $A=$ $\left\{\left(x_{i}, u_{A}\left(x_{i}\right), v_{A}\left(x_{i}\right)\right) \mid x_{i} \in X\right\}$, misalkan

$$
E_{f}(A)=\frac{1}{n} \sum_{i=1}^{n} f\left(\frac{u_{A}\left(x_{i}\right)-v_{A}\left(x_{i}\right)}{1+\pi_{A}\left(x_{i}\right)}\right) .
$$

Maka $E_{f}(A)$ adalah suatu ukuran entropi untuk IFS.

$E_{f}(A)$ yang didefinisikan pada (3.2) merupakan suatu ukuran entropi.

\subsection{Perbandingan Ukuran Entropi Baru dengan Ukuran Entropi yang Ada}

Untuk $A \in I F S(X)$, Ye [12] mengusulkan dua ukuran entropi $J_{1}(A)$ dan $J_{2}(A)$ :

$$
\begin{aligned}
& J_{1}(A)=\frac{1}{n} \sum_{i=1}^{n}\left\{\left[\sin \frac{1+u_{A}\left(x_{i}\right)-v_{A}\left(x_{i}\right)}{4} \pi+\sin \frac{1-u_{A}\left(x_{i}\right)+v_{A}\left(x_{i}\right)}{4} \pi-1\right] \frac{1}{\sqrt{2}-1}\right\}, \\
& J_{2}(A)=\frac{1}{n} \sum_{i=1}^{n}\left\{\left[\cos \frac{1+u_{A}\left(x_{i}\right)-v_{A}\left(x_{i}\right)}{4} \pi+\cos \frac{1-u_{A}\left(x_{i}\right)+v_{A}\left(x_{i}\right)}{4} \pi-1\right] \frac{1}{\sqrt{2}-1}\right\} .
\end{aligned}
$$

Proposisi berikut menunjukkan bahwa $J_{1}(A)=J_{2}(A)$. 
Proposisi 3.3. [10] Untuk suatu $A=\left\{\left(x_{i}, u_{A}\left(x_{i}\right), v_{A}\left(x_{i}\right)\right) \mid x_{i} \in X\right\}$, misalkan

$$
J(A)=\frac{1}{n} \sum_{i=1}^{n}\left\{\left[\sqrt{2} \cos \frac{u_{A}\left(x_{i}\right)-v_{A}\left(x_{i}\right)}{4} \pi-1\right] \frac{1}{\sqrt{2}-1}\right\},
$$

maka $J_{1}(A)=J_{2}(A)=J(A)$.

Teorema 3.4. [10] Misalkan $X=\{x\}$. Untuk suatu konstanta a di $(0,1]$, misalkan $F_{a}=\left\{\left(x, u_{A}(x), v_{A}(x)\right) \mid x \in X\right\} \in I F S(X)$, dengan $\left|u_{A}(x)-v_{A}(x)\right|=$ a. Maka $E(A)$ monoton naik dengan $\pi_{A}(x)$ di $F_{a}$.

Dari perbandingan ukuran entropi $E(A)$ dan $J(A)$, diketahui bahwa $E(A)$ dapat mengukur tidak hanya tingkat kekaburan, tetapi juga tingkat intuisionisme dari IFS, yang mengatasi kelemahan $J(A)$ yang hanya bisa mengukur tingkat kekaburan dari IFS. Ukuran entropi yang diusulkan oleh Xia dan Xu [11], yaitu:

$$
\begin{aligned}
E_{X M}^{q}(A)= & -\frac{1}{n T} \sum_{i=1}^{n}\left\{\left[1+q\left(1-u_{A\left(x_{i}\right)}\right)\right] \ln \left[1+q\left(1-u_{A}\left(x_{i}\right)\right)\right]\right. \\
& +\left[1+q\left(1-v_{A}\left(x_{i}\right)\right)\right] \ln \left[1+q\left(1-v_{A}\left(x_{i}\right)\right)\right] \\
& -\left[1+q\left(1-u_{A}\left(x_{i}\right)\right)+1+q\left(1-v_{A}\left(x_{i}\right)\right)\right] \\
& {\left.\left[\ln \left(1+q\left(1-u_{A}\left(x_{i}\right)\right)+1+q\left(1-v_{A}\left(x_{i}\right)\right)\right)-\ln 2\right]\right\}+1, }
\end{aligned}
$$

dimana $T=(1+q) \ln (1+q)-(2+q)(\ln (2+q)-\ln 2), q>0$.

Vlachos dan Sergiadis [8] [9] mengusulkan dua ukuran entropi, yaitu:

$$
\begin{aligned}
E_{V S 1}= & -\frac{1}{n \ln 2} \sum_{i=1}^{n}\left[u_{A}\left(x_{i}\right) \ln u_{A}\left(x_{i}\right)+v_{A}\left(x_{i}\right) \ln v_{A}\left(x_{i}\right)\right. \\
& \left.-\left(1-\pi_{A}\left(x_{i}\right)\right) \ln \left(1-\pi_{A}\left(x_{i}\right)\right)-\pi_{A}\left(x_{i}\right) \ln 2\right], \\
E_{V S 2}= & \frac{1}{n} \sum_{i=1}^{n} \frac{2 u_{A}\left(x_{i}\right) v_{A}\left(x_{i}\right)+\pi_{A}^{2}\left(x_{i}\right)}{u_{A}^{2}\left(x_{i}\right)+v_{A}^{2}\left(x_{i}\right)+\pi_{A}^{2}\left(x_{i}\right)} .
\end{aligned}
$$

Ketiga ukuran entropi di atas memenuhi persyaratan pada Definisi ukuran entropi.

Teorema 3.5. [10] Misalkan $X=\{x\}$. Untuk suatu konstanta a di $(0,1)$, misalkan $F_{a}=\left\{\left(x, u_{A}(x), v_{A}(x)\right) \mid x \in X\right\} \in I F S(X)$, dengan $\left|u_{A}(x)-v_{A}(x)\right|=a$. Maka

(1) $E_{V S 1}(A)$ adalah monoton turun dengan $\pi_{A}(x)$ di $F_{a}$;

(2) Ketika $0 \leq \pi_{A}(x)<\frac{1}{3}, E_{V S 2}(A)$ adalah monoton turun dengan $\pi_{A}(x)$ di $F_{a}$; Ketika $\frac{1}{3}<\pi_{A}(x) \leq 1, E_{V S 2}(A)$ adalah monoton naik dengan $\pi_{A}(x)$ di $F_{a}$.

\section{Kesimpulan}

Berdasarkan hasil pada pembahasan diperoleh kesimpulan sebagai berikut:

(1) Ukuran entropi adalah ukuran untuk mengukur tingkat kekaburan atau tingkat ketidakjelasan suatu himpunan kabur (Fuzzy Set).

(2) Fungsi bernilai riil

$$
E(A)=\frac{1}{n} \sum_{i=1}^{n} \cos \frac{u_{A}\left(x_{i}\right)-v_{A}\left(x_{i}\right)}{2\left(1+\pi_{A}\left(x_{i}\right)\right)} \pi
$$


untuk suatu $A=\left\{\left(x, u_{A}(x), v_{A}(x)\right) \mid x \in X\right\} \in I F S(X)$, merupakan suatu ukuran entropi.

(3) Ukuran entropi $E(A)$ lebih efektif dan masuk akal untuk mengukur tingkat kekaburan dari IFS dibandingkan dengan beberapa ukuran entropi yang sudah ada.

\section{Ucapan Terima kasih}

Penulis mengucapkan terima kasih kepada Dr. Admi Nazra, Nova Noliza Bakar, M.Si, Monika Rianti Helmi, M.Si dan Narwen, M.Si yang telah memberikan kritikan dan saran sehingga makalah ini dapat diselesaikan dengan baik.

\section{Daftar Pustaka}

[1] Atanassov, K. and G. Gargov. 1989. Interval Valued Intuisionistic fuzzy Sets. Fuzzy Sets and Systems. 31: 343 - 349

[2] Burillo, P. and H. Bustince. 1996. Entropy on Intuitionistic fuzzy Sets and on Interval-valued Fuzzy Sets. Fuzzy Sets and Systems. 78: $305-316$

[3] Bustince, H. and P. Burillo. 1996. Vague Sets are Intuitionistic Fuzzy Sets. Fuzzy Sets and Systems. 79: $403-405$

[4] Huang, G.S. and Y.S. Liu. 2005. The Fuzzy Entropy of Vague Sets based on non-fuzzy sets. Computer Applications and Software. 22:16 - 17

[5] Hung, W.L. and M.S. Yang. 2006. Fuzzy Entropy on Intuitionistic Fuzzy Sets. International Journal of Intelligent System. 21: 443 - 451

[6] Luca, A. De and S. Termini. 1972. A definition of a Nonprobabilistic Entropy in The Setting of Fuzzy Sets Theory. Information and Control. 20: $301-312$

[7] Szmidt, E. and J. Kacprzyk. 2001. Entropy for Intuitionistic Fuzzy Sets. Fuzzy Sets and Systems. 118: $467-477$

[8] Vlachos, I.K. and G.D. Sergiadis. 2006. Inner Product Based Entropy in The Intuitionistic Fuzzy Setting. International Journal of Uncertainty, Fuzziness and Knowledge-Based System. 14: 351 - 366

[9] Vlachos, I.K. and G.D. Sergiadis. 2007. Intuitionistic Fuzzy Information Application to Pattern Recognition. Pattern Recognition Letters. 28: 197 - 206

[10] Wei, C. and Z. Yuzhong. 2015. Entropy Measures for Interval-valued Intuitionistic Fuzzy Sets and Their Application in Group Decision Making. Hindawi Publishing Corporation Mathematical Problem in Engineering. 2015: 1 - 7

[11] Xia, M.M and Z.S. Zu. 2012. Entropy/Cross Entropy-Based Group Decision Making Under Intuitionistic Fuzzy Environment. Information Fusion. 13: 31 47

[12] Ye, J. 2010. Two Effective Measures of Intuitionistic Fuzzy Entropy. Computing. 87: $55-62$

[13] Zadeh, L.A. 1965. Fuzzy Sets. Fuzziness and Knowledge-Based Systems. 16: $529-555$

[14] Zadeh, L.A. 1965. Fuzzy Sets. Information and Computation 8: $338-353$ 